\title{
La Influencia de las Emociones y el Impacto en la Productividad de los Trabajadores de una Microempresa Comercializadora de Plásticos
}

\author{
Daniela Villegas Reyes, \\ Dr. Salvador Neme Calacich, \\ Dra. Aída Dinorah García Álvarez, \\ Universidad Juárez Autónoma de Tabasco, \\ División Académica Ciencias Económico Administrativas, México
}

URL:http://dx.doi.org/10.19044/esj.2020.v16n10p56

\section{Resumen}

Esta investigación tiene como objetivo conocer la influencia de las emociones en la productividad de los trabajadores en una microempresa comercial. El tipo de investigación es descriptivo. El instrumento que se utilizó para recopilar los datos es una encuesta que constaba de 11 ítems con escala Likert, su aplicación estaba dirigida a una población de 8 personas que trabajan y configuran las áreas estratégicas de la empresa. El método utilizado es cuantitativo, ya que se desea conocer cómo influyen las emociones en la productividad de los trabajadores. Los resultados obtenidos fueron que las emociones influyen en la productividad de los trabajadores, de acuerdo con diversas condiciones que se presentan en el entorno personal y laboral. La conclusión es que tanto las emociones positivas como negativas tienen un impacto en la productividad de los trabajadores, por lo tanto, los superiores de esta empresa deben tomar medidas, adecuadas para fortalecer las primeras y evitar el crecimiento de las segundas, para que la productividad no se vea afectada.

Palabras claves: Emociones, productividad, comportamiento organizacional, desempeño laboral 


\title{
The Influence of Emotions and the Impact on the Productivity of the Workers of a Plastics Trading Company
}

\author{
Daniela Villegas Reyes, \\ Dr. Salvador Neme Calacich, \\ Dra. Aída Dinorah García Álvarez, \\ Universidad Juárez Autónoma de Tabasco, \\ División Académica Ciencias Económico Administrativas, México
}

\begin{abstract}
This research aims to know the influence of emotions on the productivity of workers in a commercial microenterprise. The type of research is descriptive. The instrument that was used to collect the data is a survey consisting of 11 items with Likert scale, its application was aimed at a population of 8 people who work and shape the strategic areas of the company. The method used is quantitative, since it is desired to know how emotions influence the productivity of workers. The results obtained were that emotions influence the productivity of workers, according to various conditions that arise in the personal and work environment. The conclusion is that both positive and negative emotions have an impact on workers' productivity, therefore, the superiors of this company must take appropriate measures to strengthen the former and prevent the growth of the latter, so that productivity is not affected.
\end{abstract}

Keywords: Emotions, productivity, organizational behaviour, work performance

\section{Introduction}

La presente investigación es realizada con la finalidad de obtener conocimientos acerca de cómo influyen las emociones en la productividad de los trabajadores en una microempresa comercializadora de plásticos. Las emociones son reacciones psicológicas que todos los humanos podemos sentir, percibir o experimentar, estas pueden ser positivas o negativas. Es por esto que el autor Lolas S. (2008) define las emociones:

"Lo que mejor describiría lo que es una emoción (título de un trabajo clásico de William James) es que se trata de un síndrome en que 
participan lo motor (la expresión), lo vivencial (la experiencia) y lo social (la manifestación pública interpretada por los otros en ese proceso que los etólogos llamaron "semantización" de la conducta aludiendo a su carácter de señal significativa)” (P. 152).

Además, estas pueden provocar que las personas cometan acciones inmorales o indebidas solo por el hecho de guiarse de sus emociones sin pensar lo que están haciendo.

Una problemática que puede surgir al percibir emociones negativas es la baja productividad de los trabajadores, por cual los autores Galindo \& Ríos (2015) definen la productividad como, "una medida de qué tan eficientemente utilizamos nuestro trabajo y nuestro capital para producir valor económico" (P. 2).

Las emociones se consideran respuestas individuales procesadas internamente por cada persona, de acuerdo a sus experiencias, por ello hace que los miembros de una organización se vean afectados por la actitud positiva o negativa que muestran hacia sus compañeros, provocando situaciones laborales inestables en distintas áreas de la empresa entre ellas rotación de personal, trabajo en equipo y la toma de decisiones.

Por lo mencionado anteriormente, el objetivo principal es conocer si las emociones influyen en la productividad de los trabajadores, así como conocer cuáles son las emociones, de acuerdo con determinadas situaciones, que más influyen en las actividades de estos.

\section{Revisión de literature}

Las emociones forman parte del ser humano y son indispensable para expresar ideas y la comunicación entre las personas. De igual manera las emociones, por medio de las personas, ayudan a que las empresas puedan lograr los objetivos establecidos.

Razón por la cual el autor Sosa (2007) define las emociones como “información, ya que dicen muchas cosas de sí mismo: cómo se siente, qué le sucede, qué está pasando a su alrededor, pero las emociones pueden evolucionar con el fin de asegurar nuestra supervivencia" (P. 12).

Según Hellriegel \& W. Slocum (2009), clasifican a las emociones en 2 tipos, las emociones negativas que están integradas por la ira, miedo, culpa, tristeza, envidia, desagrado y las emociones positivas, felicidad, orgullo, amor y alivio.

Las emociones dentro de una organización influyen en lo que se le conoce como el comportamiento organizacional ya que depende de estas la manera en que se desenvolverán los trabajadores.

Por lo que los autores P. Robbins \& Timothy (2009) definen el comportamiento organizacional como "Un campo de estudio que investiga el 
efecto que los individuos, grupos y estructura tienen sobre el comportamiento dentro de las organizaciones, con el propósito de aplicar dicho conocimiento para mejorar la efectividad de las organizaciones" (P. 10).

De acuerdo con Palaci (2005) citado por Pedraza, Amaya \& Conde (2015), plantea que: "el desempeño laboral es el valor que se espera aportar a la organización de los diferentes episodios conductuales que un individuo lleva acabo en un período de tiempo" (P. 496).

Que las personas de una organización experimenten emociones positivas y que estas influyan en las demás personas de manera positiva ayuda a que el ambiente laboral sea el adecuado e incremente la productividad (Ayala y Cardona, 2016).

De igual manera, Goleman (2000) citado por Díaz (2014) menciona que "el autocontrol emocional o las habilidades de comunicación, tienen un impacto enorme en el clima laboral de los equipos y también propone que dicho clima laboral puede representar entre un $20 \%$ y un $30 \%$ de la productividad de dicho equipo" (Párr. 5). Esto indica que las emociones si influyen en la productividad de las personas que laboran en las empresas.

En este contexto, Moreno (1995) afirma que la productividad "se interesa en la utilización eficiente y eficaz de los recursos al producir esos bienes y servicios" (P. 3). Asimismo, el autor Pérez (2012) afirma que "las emociones afectan las actitudes y el comportamiento en el lugar de trabajo, lo que trae grandes repercusiones en la productividad" (Párr. 3).

Del mismo modo, el autor Fleischhacker (2014) afirma "para que la productividad laboral sea efectiva es necesario tener en cuenta que la inteligencia emocional en un nivel elevado procura la estabilidad personal de los colaboradores de una empresa" (P.67).

Asimismo, la manera en que se afecta la productividad de las personas son por las actitudes que los jefes superiores presentan, es decir, las emociones que reflejan ante el personal, por ejemplo, tristeza, enojo, alegría, si las emociones son positivas la productividad aumenta, en caso contrario la productividad disminuye (Randstad, 2017).

De igual forma los autores López, Pulido y Augusto (2013) citado por Ayuso (2016) señala que las emociones influyen en diferentes aspectos en el trabajo tales como la productividad, rendimientos y el clima organizacional (P. 15).

Por esta razón, Vallejo (2019) señala que "debemos aprender a controlar, tanto en el ámbito personal como en el profesional, las propias emociones y las reacciones frente a éstas, para no incurrir en conductas violentas, verbal o físicamente" (Párr. 4).

Por esto, el miedo es una de las emociones que influyen en los empleados, cuando se experimenta esta emoción, el nivel de rendimiento es menor y esto perjudica el ambiente de la empresa (Sosa, 2007). 
Desde otro punto, la Asociación Española Contra el Cáncer (2019) menciona las categorías básicas de las emociones, la cual se presentan en la siguiente tabla:

Tabla 1: Categorías básicas de las emociones

\begin{tabular}{|c|c|}
\hline MIEDO & $\begin{array}{l}\text { Anticipación de una amenaza o peligro (real o } \\
\text { imaginario) que produce ansiedad, incertidumbre, } \\
\text { inseguridad. }\end{array}$ \\
\hline SORPRESA & $\begin{array}{l}\text { Sobresalto, asombro, desconcierto. } \\
\text { Es muy transitoria y nos permite una aproximación } \\
\text { cognitiva para saber qué está ocurriendo. }\end{array}$ \\
\hline AVERSIÓN & Disgusto o asco hacia aquello que tenemos delante. \\
\hline IRA & $\begin{array}{l}\text { Rabia, enojo que aparece cuando las cosas no salen } \\
\text { como queremos o nos sentimos amenazados por } \\
\text { algo o alguien. }\end{array}$ \\
\hline ALEGRÍA & $\begin{array}{l}\text { Sensación de bienestar y de seguridad que sentimos } \\
\text { cuando conseguimos algún deseo o vemos } \\
\text { cumplida alguna ilusión. }\end{array}$ \\
\hline TRISTEZA & $\begin{array}{l}\text { Pena, soledad, pesimismo ante la pérdida de algo } \\
\text { importante o cuando nos han decepcionado. }\end{array}$ \\
\hline
\end{tabular}

Fuente: Las emociones. Comprenderlas para vivir mejor (AECC, 2019)

Las emociones influyen en la toma de decisiones, es como menciona el autor Ayuso (2016), al momento de tomar decisiones la razón se interpone, pero esta es influida por las emociones por más que se quiera usar la razón los sentimientos salen a relucir.

\section{Materiales y Método}

Esta investigación se realizó en una microempresa comercial dedicada a la distribución de plásticos.

El enfoque de la investigación es cuantitativo, descriptivo pues los autores Hernández, Fernández \& Baptista (2006) consideran que este enfoque "ofrece la posibilidad de generalizar los resultados más ampliamente, nos otorga control sobre los fenómenos, así como un punto de vista de conteo y las magnitudes de éstos. Asimismo, nos brinda una gran posibilidad de réplica y un enfoque sobre puntos específicos de tales fenómenos" (P. 21).

La elección de este enfoque fue porque se desea conocer la influencia que tienen diversas emociones en relación con la productividad, es decir, conocer si las emociones influyen de acuerdo a ciertas situaciones en la productividad de los empleados.

El alcance de esta investigación es de tipo descriptiva, de acuerdo con Hernández Fernández \& Baptista (2014) los estudios descriptivos "buscan especificar las propiedades, las características y los perfiles de personas, 
grupos, comunidades, procesos, objetos o cualquier otro fenómeno que se someta a un análisis" (P. 92).

Primeramente, se aplicó una encuesta piloto a 5 de 8 trabajadores que conforman la plantilla laboral de la empresa, la cual constaba de doce preguntas con la finalidad de comprobar si las preguntas que se planteaban eran claras y entendibles por los trabajadores de la empresa.

Posteriormente se volvió aplicar la encuesta a 8 de los trabajadores que conforman la plantilla laboral, los cuales pertenecen al área administrativo y operativo de la empresa, la cual se modificó y constó de 11 preguntas con escala de Likert donde:

- 1 es "totalmente de acuerdo"

- 2 es "de acuerdo"

- 3 es "no opina"

- 4 es "en desacuerdo"

- 5 es "totalmente en desacuerdo"

Y una pregunta abierta la cual se pidió que la justificaran.

La encuesta aplicada, a los trabajadores en la empresa, se elaboró con base en el instrumento utilizado por el autor Sosa (2007).

\section{Resultados}

De la aplicación de la encuesta a 8 trabajadores en la microempresa Plásticos Mendoza S. A. de C.V. (3 son mujeres lo que equivale a $38 \%$ y 5 son hombres a lo que equivale a un $62 \%$ ), los resultados fueron los siguientes:

El rango de edad de los trabajadores de dicha empresa es entre los 20 y 50 años donde el $37 \%$ tienen entre 20 y 35 años, el $50 \%$ tiene entre 35 y 50 años y un $13 \%$ tiene más de 50 años. Todos estos trabajadores tienen un nivel de puesto donde un $12 \%$ pertenecen a la alta gerencia, un $38 \%$ al administrativo y el $50 \%$ al operativo, con una antigüedad laboral desde los 6 meses hasta más de 21 años. Estos cuentan con un salario semanal entre los $\$ 1500$ y más de $\$ 3000$ de acuerdo con el puesto de trabajo que desempeñan.

Se percibe que dentro de esta empresa hay 3 tipos de generaciones laborando, las cuales son "baby boomers", "generación x" y "generación y". Estas generaciones tienen diferentes características lo que genera que tengan distintas formas de pensar y analizar el contexto acorde a sus emociones, lo que permitiría realizar un estudio a futuro sobre sus estados afectivos que consideran las emociones positivas y negativas. 
1. Me frustro cuando mis sugerencias no son tomadas en cuenta y ya no me dan ánimo de participar.
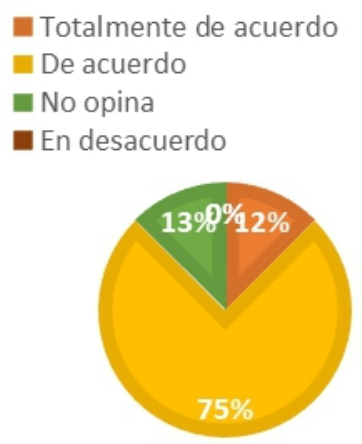

Ilustración 1. Porcentajes de la pregunta 1

La ilustración 1, muestra que la mayoría de los trabajadores sienten frustración debido a que cuando dan sugerencias u opiniones no las toman en cuenta lo que tiende a pasar es que los trabajadores se desaniman y no vuelven a opinar y siguen las ordenes que se les dictan.

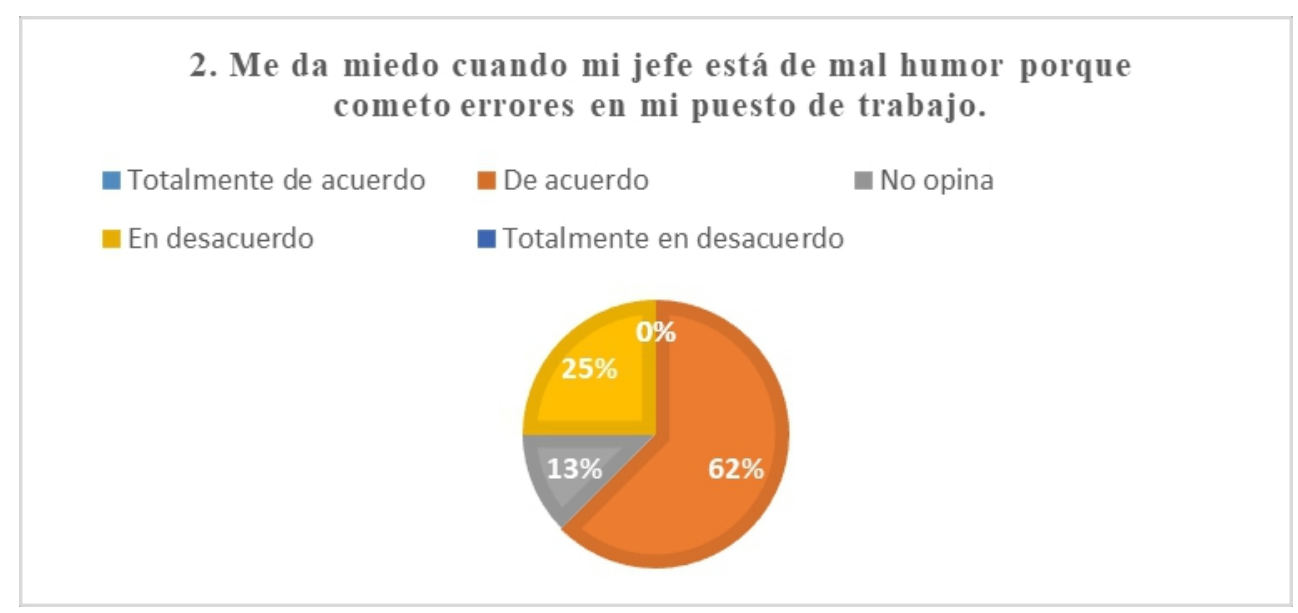

Ilustración 2. Porcentajes de la pregunta 2

Respecto a la ilustración 2 la actitud de las personas, que se encuentran alrededor, provoca que el trabajador experimente una emoción negativa (miedo), lo que a su vez afecta en sus actividades. 


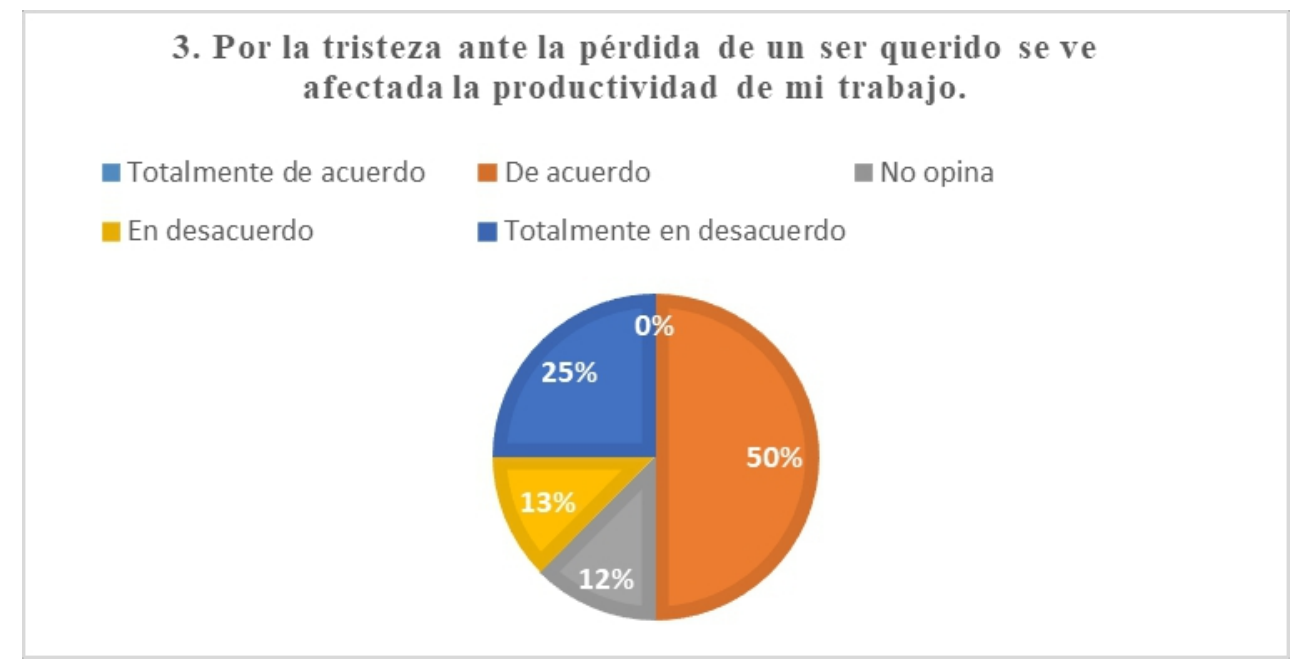

Ilustración 3. Porcentajes de la pregunta 3

De acuerdo con la pregunta número 3, la tristeza es una emoción que afecta en gran medida la productividad de los trabajadores y esta es percibida cuando fallece un ser querido.

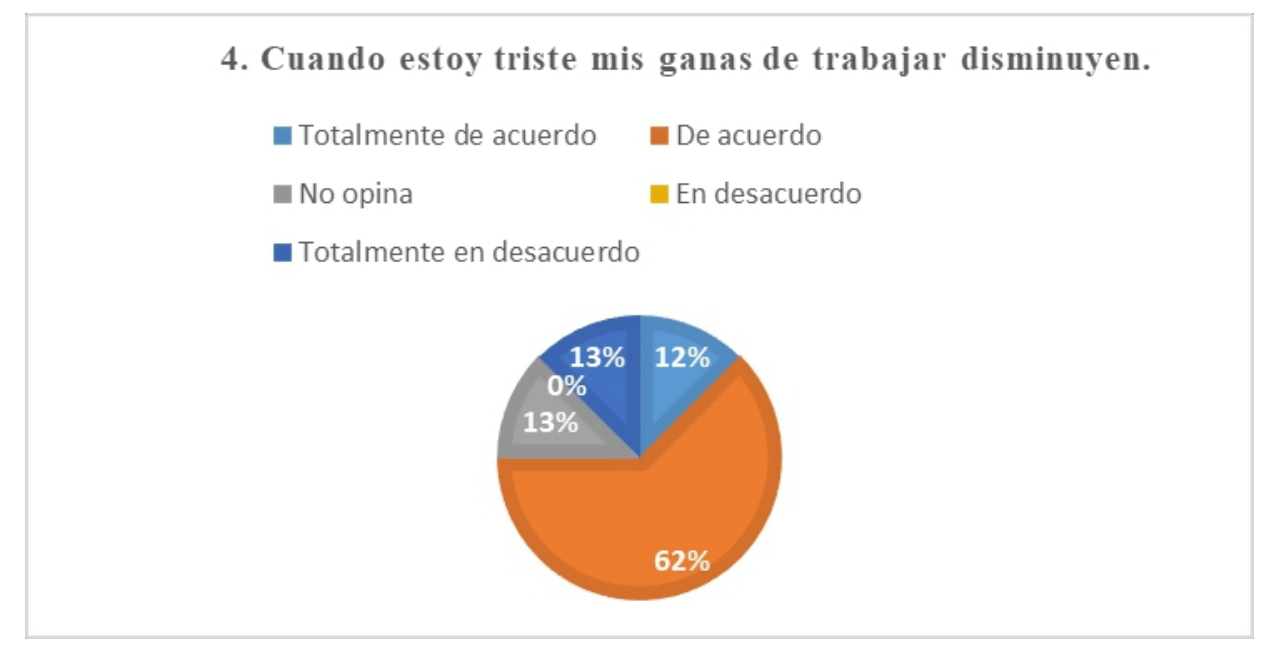

Ilustración 4. Porcentajes de la pregunta 4

La ilustración 4 muestra que en gran porcentaje los trabajadores, cuando están triste, tienden a sentir desinterés en hacer sus actividades lo que indica que su productividad disminuye. 


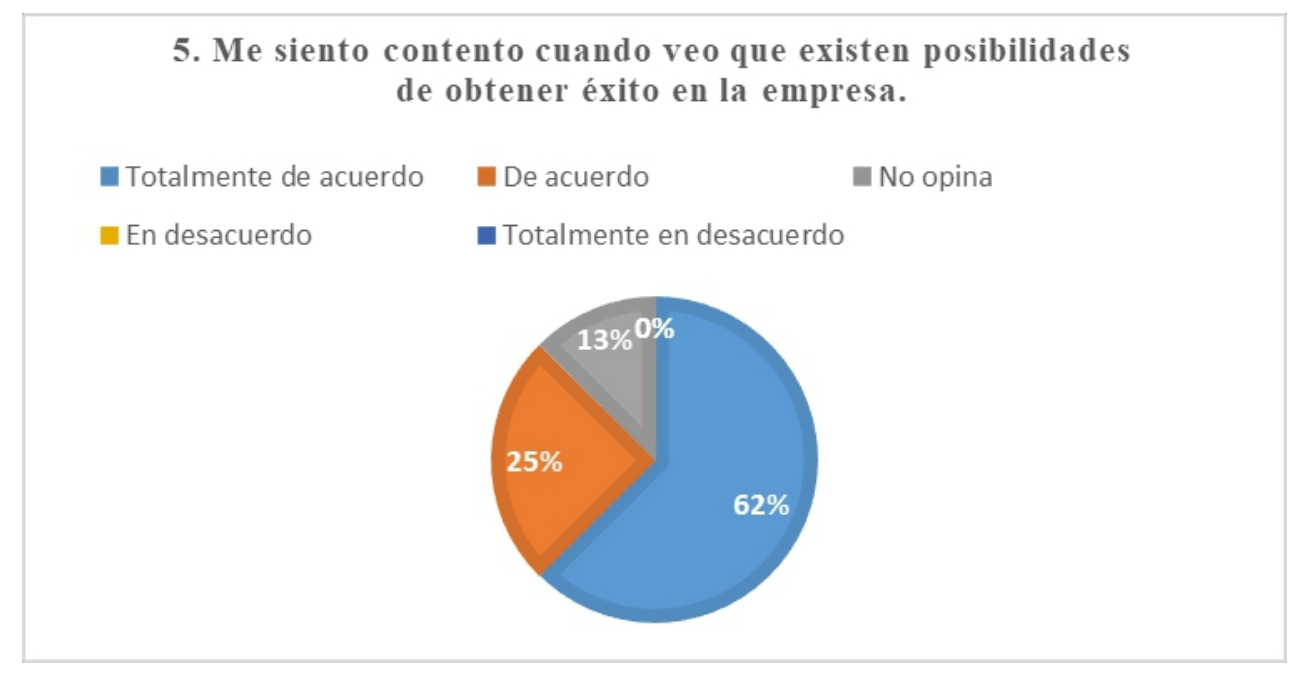

Ilustración 5. Porcentajes de la pregunta 5

De acuerdo con la ilustración 5, los trabajadores perciben que pueden obtener éxito en la empresa, esto mediante el ascenso de puesto, lo que provoca que estos se sientan contentos.

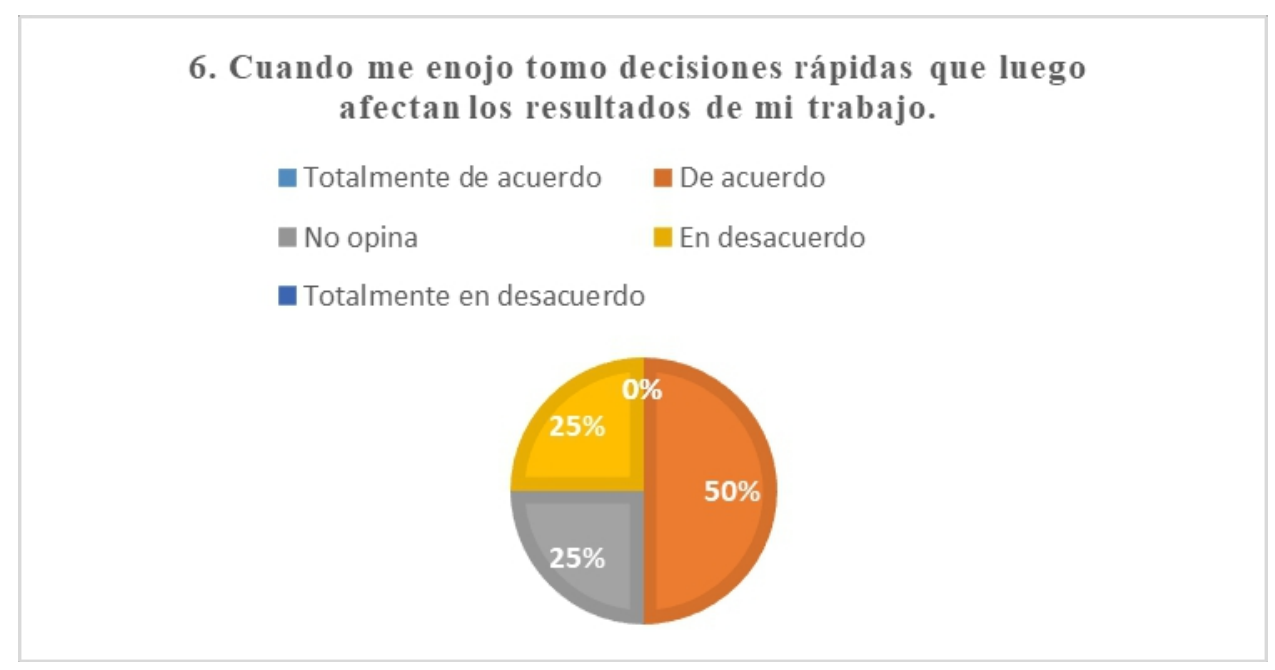

Ilustración 6. Porcentajes de la pregunta 6

En la ilustración 6, se puede apreciar que los trabajadores llegan a tomar malas decisiones cuando están enojados, lo que provoca una reducción en la eficiencia de sus labores, como consecuencia del poco o nulo compromiso con el puesto que desempeña. 
7. Cuando tengo problemas sentimentales siento menos

ganas de trabajar.

- Totalmente de acuerdo $\quad$ De acuerdo
No opina
- Totalmente en desacuerdo

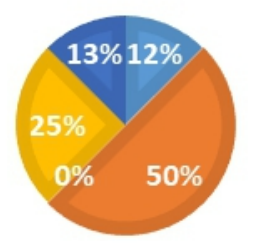

Ilustración 7. Porcentajes de la pregunta 7

En la ilustración 7, se puede observar que los problemas sentimentales como discusiones de pareja, entre otros casos, afectan la productividad de los trabajadores ya que las ganas de trabajar son bajas.

8. Cuando tengo problemas económicos no logro concentrarme en mis tareas.

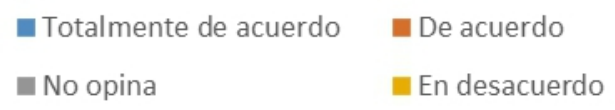

- Totalmente en desacuerdo

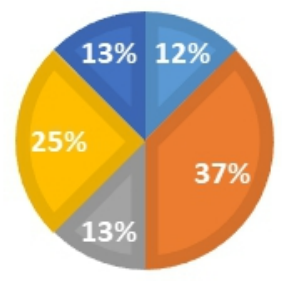

Ilustración 8. Porcentajes de la pregunta 8

Respecto a la ilustración 8 , los problemas económicos es una situación en donde la mitad de los trabajadores consideran los altera de cierta manera, ya que no se concentran en lo que están haciendo y eso afecta en su productividad. 
9. Cuando estoy ansioso (nervioso) tiendo a cometer errores por falta de concentración.
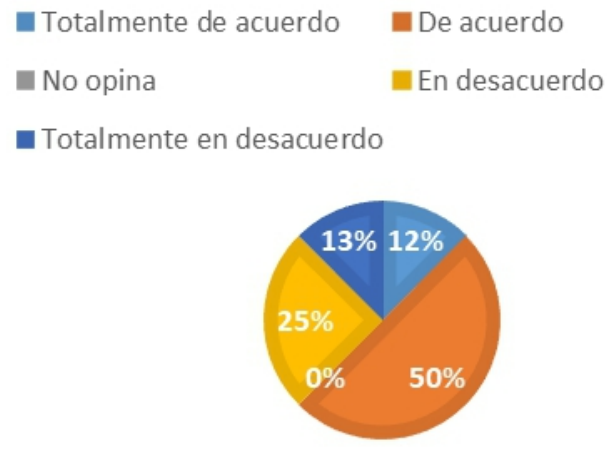

Ilustración 9. Porcentajes de la pregunta 9

En la ilustración 9, indica que el nerviosismo provoca en los trabajadores la desconcentración, esto debido a que están pensando en diversas cosas, lo que lleva a cometer errores que impacten su productividad.

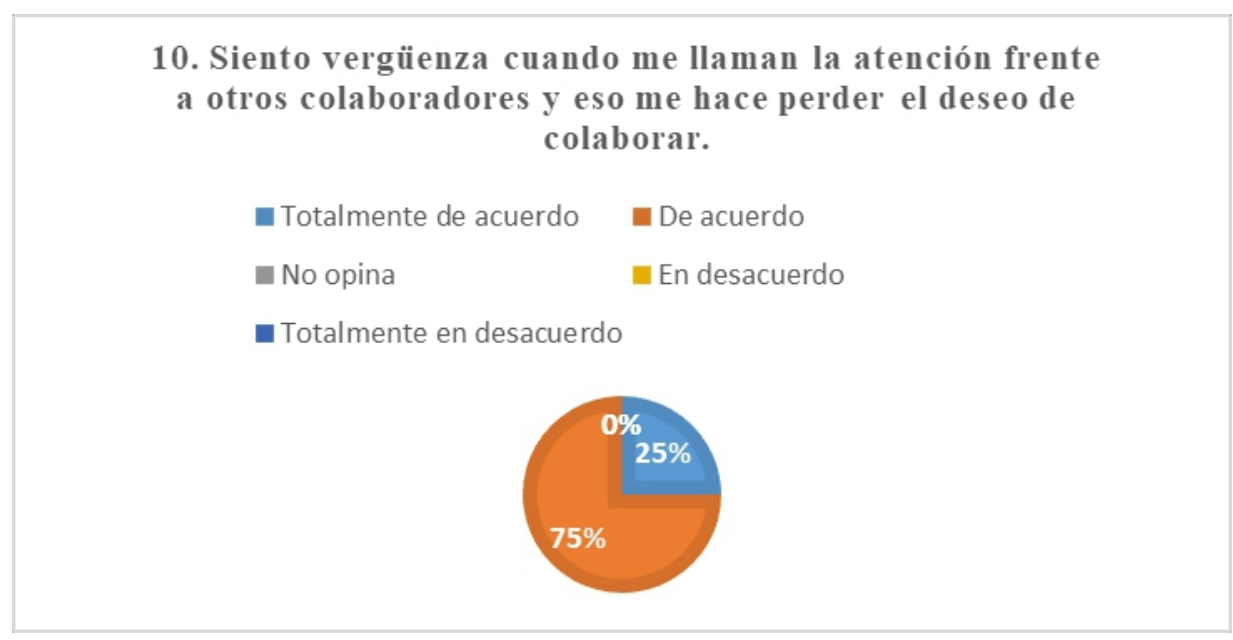

Ilustración 10. Porcentajes de la pregunta 10

Se observa en la ilustración 10, que otra manera por la cual el rendimiento de los trabajadores disminuye es por medio de situaciones donde quedan expuesto delante de otras personas, ya que presentan vergüenza y los desmotiva a seguir haciendo bien sus actividades. 
11. Denunció las faltas e injusticia que son cometidas en mi área de trabajo.
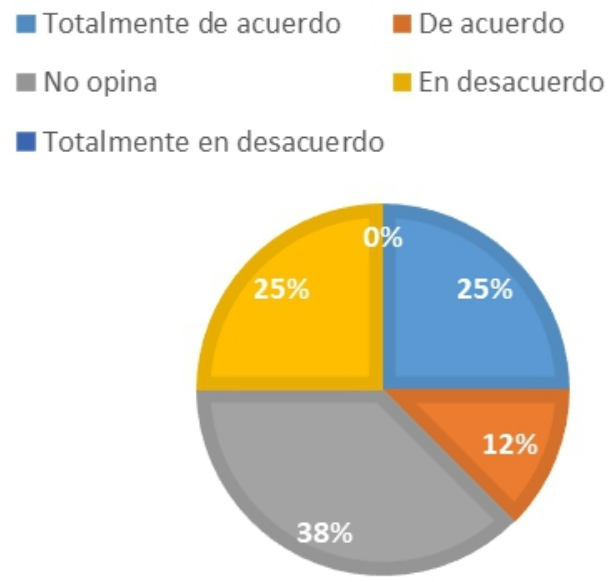

Ilustración 11. Porcentajes de la pregunta 11

Se puede observar en la ilustración 11, que la mayoría de los trabajadores no desean decir algo al respecto, sobre las malas acciones que pueden ser cometidas durante su jornada laboral, esto debido a las acciones que puedan ser tomadas por los superiores.

\section{Conclusiones}

Los resultados obtenidos, mediante el instrumento utilizado, se puede afirmar lo que mencionan los autores López, etal. (2013) citado por Ayuso (2016) que las emociones influyen en la productividad de los trabajadores de una empresa, en este caso la microempresa Plásticos Mendoza S.A. DE C.V., ya sea por diversas situaciones que se presentan tanto en la vida personal como en lo laboral.

De acuerdo a los objetivos planteados, se concluye que las emociones si influyen en la productividad de los trabajadores ya sea por exclusión del equipo de trabajo, motivos personales, etc. Aunque esto también depende del ambiente laboral que se perciba en las empresas, ya que suele suceder que hay envidia, miedo, rencor, injusticias, entre los propios compañeros de trabajo.

De igual manera se llega a la conclusión que las emociones negativas son las que más afectan en la productividad de estos trabajadores ya que como su nombre lo indica son perjudiciales, estas no ayudan a que se realice el trabajo de la mejor forma.

En esta microempresa la alegría es una de las emociones que influyen en la productividad, ya que sienten que el esfuerzo que hacen en esta se verá reflejado en un futuro. 
Aunque las emociones negativas también influyen en los trabajadores, ya que la productividad disminuye cuando están triste, enojados, nerviosos, sin embargo, en ciertas ocasiones no todo el tiempo andan en esas situaciones. El miedo es una de las emociones que más se hace presente en los trabajadores, ya que cuando hay ciertas acciones injustas los trabajadores temen decirlas por el motivo de que piensan que los van a despedir o no les darán la razón, lo que origina la desmotivación a seguir realizando sus actividades de la manera correcta, lo que provoca la baja productividad.

Las emociones deben ser tomadas en cuenta por el personal perteneciente al alto directivo en este caso al gerente, ya que puede llegar afectar la productividad y el rendimiento económico de esta microempresa.

Las emociones conllevan a tomar decisiones que pueden ser beneficiosas para esta microempresa, sin embargo, si estos sentimientos son negativos suelen tomarse malas decisiones.

\section{References:}

1. Asociación Española Contra el Cáncer. (2019). Las emociones comprenderlas para vivir mejor: AECC http://sauce.pntic.mec.es/falcon/emociones.pdf

2. Ayala Marin, A. F., \& Cardona Arango, M. (2016). Emociones y desempeño laboral. Revista Electrónica Psiconex, 7-8.

3. Ayala Marín, A. F., \& Cardona Arango, M. (2016). Emociones y desempeño laboral. Revista Electronica Psyconex, 8(12), 7-8 pp.

4. Ayuso Arcones, M. V. (2016) La inteligencia emocional en el trabajo. (Trabajo de fin de grado) Universidad de Valladolid, Facultad de Ciencias Sociales, Jurídicas y de la comunicación. España.

5. Díaz Escoto, M. Á. (2014, 6 de Mayo). RH saludable. La revista de las organizaciones saludables. https://rhsaludable.com/el-impactodel-estado-emocional-en-la-productividad-de-los-equipos/

6. Fleischhacker Pérez, I. A. (2014). Inteligencia emocional y productividad laboral (Estudio realizado con el personal de salus del centro de diagnostico por imágenes, policlínica) (Tesis de Licenciatura) Universidad Rafael Landívar Facultad de Humanidades Campus de Quetzaltenango. Guatemala.

7. Galindo, M., \& Ríos, V. (2015, Agosto). Productividad. Recuperado de

https://scholar.harvard.edu/files/vrios/files/201508_mexicoproductivi ty.pdf

8. Hellriegel, D., \& W. Slocum, J. J. (2009). Comportamiento Organizacional. (Doceava ed.) México: CENGAGE Learning. 
9. Hernandez Sampierí, R., Fernández Collado, C., \& Baptísta Lucio, P. (2006). Metodología de la investiación (Sexta ed.). México: McGRAW-HILL/INTERAMERICANA.

10. Hernadez Sampieri, R., Fernández Collado, C., \& Baptista Lucio, M. d. (2014). Metodología de la investigación (Sexta ed.). México: McGraw Hill.

11. Lolas S., F. (2008). Las emociones. Revista Chilena de Neuropsiquiatría, 46(2), 152p. https://dx.doi.org/10.4067/S071792272008000200013

12. Moreno Villegas, O. A. (1995). Productividad y desarrollo económico. (Tesis de Licenciatura) Universidad de Sonora división de ingeniería. México.

13. Pedraza, E., Amaya, G., \& Conde, M. (2015). Desempeño laboral y estabilidad del personal administrativo contratado de la facultad de medicina de la Universidad del Zulia. Revista de Ciencias Sociales. 16(32), 496p.

14. Pérez, S. (2012, 9 de Mayo). Herramientas de gestión organizacional. http://go-tools.blogspot.com/2012/05/emociones-dentro-de-lasorganizaciones_09.html

15. P. Robbins, S., \& Timothy, A. J. (2009). Comportamiento organizacional. (Quinta ed.) México: Pearson educación.

16. Randstand. (2017, 30 de Marzo). Emociones y liderazgo: Impacto en el clima y productividad. https://www.randstad.cl/tendencias360/archivo/emociones-yliderazgo-impacto-en-el-clima-y-productividad_1406

17. Sosa Giron, A. S. (2007) Influencia de las emociones en el desempeño laboral. (Tesis de Licenciatura) Universidad de San Carlos de Guatemala Escuela De Ciencias Psicológicas. Guatemala.

18. Vallejo Briceño, J. A. (2019, 05 de Marzo). Derechos humanos. http://epn.gov.co/elearning/distinguidos/DDHH/index.html 